\title{
Review of FIGO \& ADA, WHO, IADPSG Guidelines for GDM for Low Resource Setting and Integration of DIPSI with MOHFW Govt of India, Guidelines
}

\author{
Rajesh Jain ${ }^{1, *}$, Susanne Olejas ${ }^{2}$, Lee Sam Goo ${ }^{3}$, N. Bhavatharinin ${ }^{4}$, Ashish S. Dengra ${ }^{5}$, \\ Reza Shoghli', Sanjeev Davey ${ }^{7}$, Rachna Jain ${ }^{8}$ \\ ${ }^{1}$ Gestational Diabetes Prevention Control Project, Maternal Health, National Health Mission, Lucknow, India \\ ${ }^{2}$ World Diabetes Foundation, Copenhagen, Denmark \\ ${ }^{3} 239$ Bio Inc, Jangsu-eup, South Korea \\ ${ }^{4}$ S. R. C. Diabetes Care Centre, Erode, India \\ ${ }^{5}$ Department of Medicine, Mahi Diabetes Thyroid Care \& Research Centre, Jabalpur, India \\ ${ }^{6}$ Department of Cardiology, Tehran Heart Center, Azad University of Tehran, Central Branch, Iran \\ ${ }^{7}$ Department of Community Medicine, Muzaffarnagar Medical College, Muzaffarnagar, India \\ ${ }^{8}$ Department of Obstetrics \& Gynecology, Jain Hospital, Kanpur, India
}

\section{Email address:}

drrajeshjain@diabetesasia.org (R. Jain)

${ }^{*}$ Corresponding author

To cite this article:

Rajesh Jain, Susanne Olejas, Lee Sam Goo, N. Bhavatharinin, Ashish S. Dengra, Reza Shoghli, Sanjeev Davey, Rachna Jain. Review of FIGO \& ADA, WHO, IADPSG Guidelines for GDM for Low Resource Setting and Integration of DIPSI with MOHFW Govt of India, Guidelines. International Journal of Diabetes and Endocrinology. Vol. 4, No. 3, 2019, pp. 73-82. doi: 10.11648/j.ijde.20190403.12

Received: May 21, 2019; Accepted: July 19, 2019; Published: September 4, 2019

\begin{abstract}
OGTT is performed in pregnant women by measuring the plasma glucose in fasting or non-fasting after 2-hour ingesting 75 grams of glucose (Monohydrate Dextrose Anhydrous). For diagnosing gestational diabetes (GDM) Indian Guidelines (DIPSI Test) are simple and can be done easily in low resource setting where large number of pregnant women visit for ANC check-up. The severity of GDM increases because of the action of insulin is diminished (insulin resistance) due to raised hormone secretion by the placenta. Other risk factors for GDM are being elderly, increased BMI, or obesity, weight gain in pregnancy, history of diabetes in family, stillbirth or a congenital abnormality in previous deliveries. GDM has previously been considered to be transient during pregnancy and resolve after pregnancy but, pregnant women with hyperglycaemia are at higher risk of developing GDM in subsequent pregnancies and about half of the women with a history of GDM will develop type II Diabetes within five to ten years after delivery. DIPSI simple testing protocol is endorsed by the National Health Mission (GOI) Guideline on GDM, and also endorsed by the FIGO guideline on HIP for use in South Asia. This testing protocol has been followed by Sri Lanka, Pakistan and Bangladesh in the region. Tamil-Nadu state and Uttar Pradesh states in India launched a Universal GDM Program in 2007 and 2016 respectively, covering all pregnancies by testing and managing GDM with MNT, Metformin and Insulin in most of health care facilities. Around 28,000 ANM have been given glucometers, strips, glucose 75 gm packets for implementation of the largest GDM program in Uttar Pradesh, India to date.
\end{abstract}

Keywords: FIGO Guidelines, WHO, DIPSI, GDM, HIP, DIP, NHM, MOHFW, GOI, IADPSG, ACOG, IDF, ANM, ADA, Sub-Center, NICE, CDA

\section{Introduction}

Hyperglycaemia Elevated Blood Sugar that is newly found in pregnancy is named as either gestational diabetes mellitus
(GDM) or hyperglycaemia in pregnancy. Pregnant women with slightly elevated blood glucose levels is called as having GDM. Pregnant women with substantially elevated blood glucose levels are named as women with diabetes in 
pregnancy with previously known diabetes [1], both together is known as HIP (Hyperglycaemia in pregnancy).

It has been roughly estimated that most (75-90\%) of the cases of elevated blood glucose in pregnancy are defined gestational diabetes mellitus [2]. GDM is a type of diabetes that can present in pregnant women during the first, second or third trimester of pregnancy. If it is diagnosed in the first trimester of pregnancy most likely diabetes existed before pregnancy but was undiagnosed.

GDM and diabetes in pregnancy is mostly an asymptomatic disease and may overlap with normal pregnancy symptoms.

An oral glucose tolerance test (OGTT) is therefore recommended for screening of GDM between 12-16 weeks or during $1^{\text {st }}$ ANC visit and a second test at the $24^{\text {th }}-28^{\text {th }}$ week of pregnancy [12] as universal GDM testing in all pregnant women. National guideline (NHM, GOI) fordiagnosisandmanagementofGestationalDiabetesendorsesth esinglesteptestrecommendedbyWHOfordiagnosisofGDMusin ga75gmglucose, through Oral Glucose Tolerance Test (OGTT) irrespective of the last meal with a threshold value of 2-hour BS >140 mg/dl. Guidelines advocate for universal screening of all pregnant women at first antenatal contact. If the first test is negative, second test should be done at 24-28 weeks of gestation [4, 12]. However, as per ADA guidelines high risk pregnant women are selectively screened in pregnancy in second trimester [3].

\section{Methodology}

OGTT is performed in pregnant women by measuring the plasma glucose in fasting or non-fasting after 2-hour ingesting 75 grams of glucose (Monohydrate Dextrose Anhydrous). For diagnosing gestational diabetes (GDM) Indian guidelines are simple and can be done easily in low resource setting where large number of pregnant women visit for ANC check-up. The severity of GDM increases because the action of insulin is diminished (insulin resistance) due to raised hormone secretion by the placenta [4]. Other risk factors for GDM are being elderly, increased BMI, or obesity, weight gain in pregnancy, history of diabetes in family, stillbirth or a congenital abnormality in previous deliveries.

GDM previously used to be transient during pregnancy and resolve after pregnancy but pregnant women with hyperglycaemia are at higher risk of developing GDM in subsequent pregnancies and about half of women with a history of GDM will develop type II diabetes within five to ten years after delivery.

GDM women have lifetime risk for type II diabetes and obesity [5], and adverse outcomes both for women and foetus. The most common shared features among them are hypertension and LGA large for gestation age (macrosomia). Tight control of the blood sugar during all the trimesters can reduce adverse outcomes in mother and foetus. All the women who have diabetes prior to conception need counselling, antenatal care and good management of hyperglycaemia incl. post- partum care for good outcomes.

\section{Prevalence}

As per IDF Atlas 2017, 21.3 million or 16.2\% (Figure 1) of births to pregnant women had some form of hyperglycemia in pregnancy; HIP before and during pregnancy [6]. An estimated $86.4 \%$ of HIP were due to gestational diabetes mellitus (GDM), 6.2\% due to (DIP) diabetes detected prior to pregnancy (6), and $7.4 \%$ due to other types of DM (type 1 (T1DM) and type 2 diabetes) first detected in pregnancy (Table 1). The prevalence of hyperglycemia in pregnancy (HIP) increases with the age of women and is highest at the age 45 year (around 45\%), Due to higher birth rates in early age, half of all the HIP, 49\% cases occur in women under 30 years of age (Figure 2).

The prevalence of GDM in India is 27.9 as per IDF 2017 estimated in the age group of 20-49 Years [6].

\begin{tabular}{lr}
\hline & \\
\hline Total livebirthsto women aged 20-49 years & 131.4 million \\
\hline Hyperglycaemia in pregnancy & \\
\hline Global prevalence & $16.2 \%$ \\
\hline Number of live births affected & 21.3 million \\
\hline Proportion of cases due to GDM & $86.4 \%$ \\
\hline $\begin{array}{l}\text { Proportion of cases due to other types of } \\
\text { diabetes first defectedin pregnancy }\end{array}$ & $7.4 \%$ \\
\hline $\begin{array}{l}\text { Proportion of cases due to diabetes } \\
\text { detected prior to pregnancy }\end{array}$ & $6.2 \%$ \\
\hline
\end{tabular}

Figure 1. Global Estimates of hyperglycaemia in pregnancy, 2017.

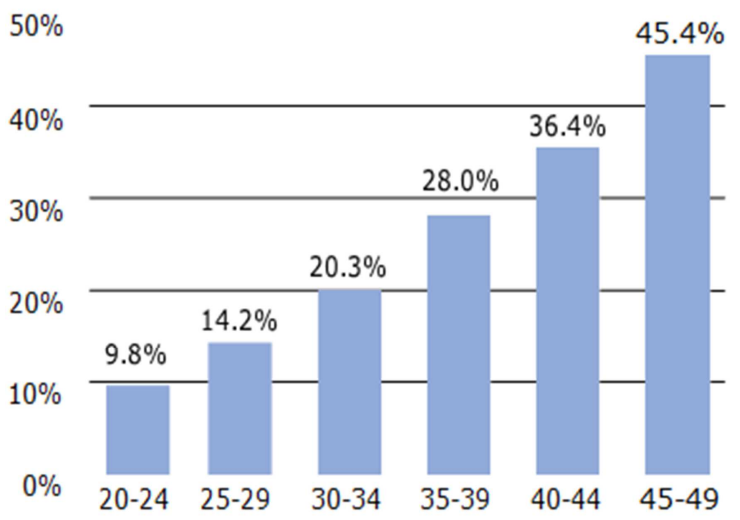

Figure 2. Hyperglycaemia in pregnancy by age group, 2017.

The prevalence of hyperglycaemia in pregnancy (HIP) varies widely around the world, with the South-East Asia Region WHO region with the highest prevalence at $24.2 \%$ compared to $10.4 \%$ in the Africa Region (Table 1). The highest number of $(88 \%)$ of cases of hyperglycaemia in pregnancy are in low- and middle-income countries (LMIC), with low access to health care facility. 
Table 1. Hyperglycaemia in pregnancy (HIP) in women aged 20-49 years by IDF region, 2017[6].

\begin{tabular}{llll}
\hline IDF region & Raw prevalence & Age-adjusted prevalence & Number of live births affected \\
\hline Africa & $10.4 \%$ & $9.5 \%$ & 3.4 million \\
Europe & $16.2 \%$ & $13.7 \%$ & 1.7 million \\
Middle East and North Africa & $21.8 \%$ & $17.9 \%$ & 3.8 million \\
North America and Caribbean & $14.6 \%$ & $12.0 \%$ & 1.0 million \\
South America and Central America & $13.1 \%$ & $11.6 \%$ & 0.9 million \\
South East Asia & $24.2 \%$ & $26.6 \%$ & 6.9 million \\
Western Pacific & $12.6 \%$ & $12.3 \%$ & 3.6 million \\
IDF Diabetes Atlas $-8^{\text {th }}$ Edition & & & \\
\hline
\end{tabular}

\section{Type of GDM}

GDM \& Diabetes in Pregnancy combined together is designated as Hyperglycaemia in Pregnancy, later one is more fatal than GDM which may be transient but if not managed adequately may leads to Diabetes later on in mother and child.

HIP = DIP + GDM (Differentiate) HIP, Type 1 \& Type II Diabetes

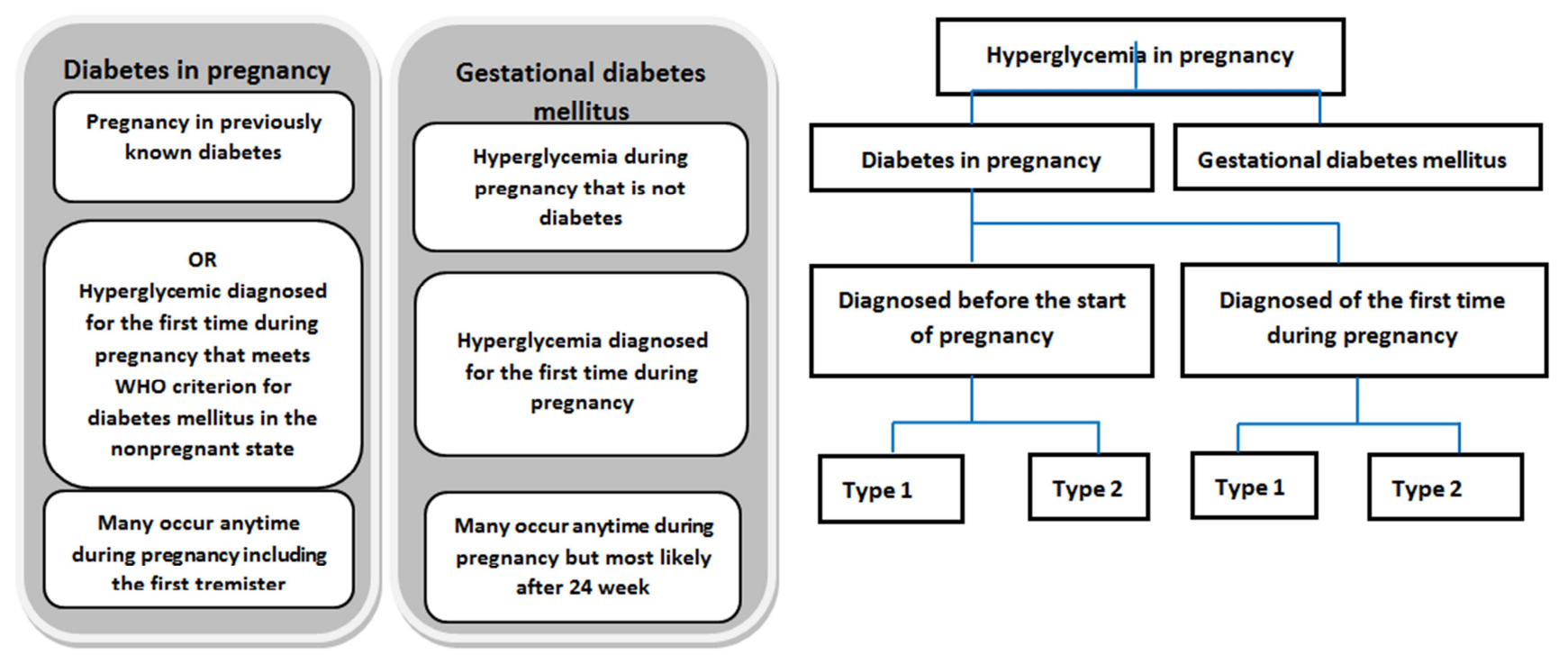

Figure 3. Hyperglycemia in Pregnancy.

\section{FIGO Recommendations \& Review of Guidelines on Hyperglycaemia in Pregnancy [4]}

1. FIGO adopts and support the IADPSG/WHO/IDF position that all pregnant women should be tested for hyperglycaemia during pregnancy using a one-step procedure.

2. FIGO encourages all countries and its member associations to adapt and promote strategies to ensure universal testing of all pregnant women of forhyperglycaemia during pregnancy

3. Universal testing:All pregnant women should be tested for hyperglycemia during pregnancy using a one-step procedure and FIGO encourages all countries and its member associations to adapt and promote strategies to ensure this.

HIP Hyperglycaemia in Pregnancy Guidelines Differ Ethnicity wise and regional wise around the world, below is the table for various important organizations Guidelines for HIP.

Table 2. Different Guidelines for GDM \& Diabetes in Pregnancy (DIP) Diagnosis.

\begin{tabular}{|c|c|c|c|c|c|}
\hline Organization & $\begin{array}{l}\text { Fasting Plasma Glucose } \\
\text { Mmol/dl }\end{array}$ & $\begin{array}{l}\text { Glucose } \\
\text { Challenge } \\
\end{array}$ & $\begin{array}{l}1 \text { h Plasma Glucose } \\
\text { Mmol/dl }\end{array}$ & 2 h Plasma Glucose & $\begin{array}{l}3 \text { h Plasma } \\
\text { Glucose }\end{array}$ \\
\hline WHO1999 & $\geq 7.0$ & $75 \mathrm{gm}$ OGTT & Not required & $\geq 7.8$ or $140 \mathrm{mg} / \mathrm{dl}$ & Not required \\
\hline $\begin{array}{l}\text { American Congress } \\
\text { Obstetricians \& Gynecologist }{ }^{2}\end{array}$ & $\geq 5.5$ & 100gm OGTT & $\geq 10.0$ & $\geq 8.6 *$ & $\geq 7.8$ \\
\hline Canada Diabetes Association ${ }^{3}$ & $\geq 5.3$ & $75 \mathrm{gm}$ OGTT & $\geq 10.6$ & $\geq 8.9$ or $160 \mathrm{mg} / \mathrm{dl}$ & Not required \\
\hline $\mathrm{IADPSG}^{4}$ & $\geq 5.1$ & $75 \mathrm{gm}$ OGTT & $\geq 10.0$ & $\geq 8.5$ or $153 \mathrm{mg} / \mathrm{dl}$ & Not required \\
\hline DIPSI $^{5}$ & - & $75 \mathrm{gm}$ OGTT & - & $\geq 7.8$ or $140 \mathrm{mg} / \mathrm{dl}$ & Not required \\
\hline
\end{tabular}


1. one value is sufficient for diagnosis

2. two or more values are required for diagnosis

3. two or more values required for diagnosis

4. one value is sufficient for diagnosis

5. one value for Diagnosis

6. one value for Diagnosis

\section{Disadvantages of the IADPSG Test \& Advantage of DIPSI Test in Asian Population}

Measuring fasting blood sugar levels and waiting while fasting for 2hours is impractical in most settings especially in South Asia and therefore drop-out rates are increased when repetition of testing for OGTT [7] is advised.

In GDM pregnant women fasting blood sugar is normal in most cases and post prandial 2-hour blood glucose is abnormal especially in the Asian context where GDM prevalence is around 14-16\% countrywide. Therefore 2-hour OGTT with 75 gm Glucose load is able to identify most
GDM cases in an Indian context [8]. Asians and especially Indians are high risk for 2-hour post prandial blood sugar increase compared to Caucasians [9].

It is estimated that fasting $\mathrm{FBG}>5.1 \mathrm{mmol} / 1$ or $92 \mathrm{mg} / \mathrm{dl}$ cut-off with $3.2 \%$ sensitivity, around $76 \%$ of pregnant women would be missed if the diagnosis is made by WHO guidelines [11].

\subsection{NHM Govt of India Guidelines for GDM}

NHM, Govt of India, MOHFW released in 2014, National Guidelines on diagnosis and management of gestational diabetes to screen all the pregnant women during the first visit and a second time at 24 weeks onwards. In addition, the Guidelines were revised in 2018 to include Metformin after 20 weeks of gestation in GDM cases after 2 weeks of MNT [12] as per the field experience and tolerability of oral drugs in the public health system as insulin cold chain maintenance is often an issue at PHC and sub-centre level health care facilities [12].

Thus, GDM is managed initially with MNT and physical exercise and if it is not controlled with MNT (lifestyle changes), Metformin or Insulin therapy is added to the MNT.

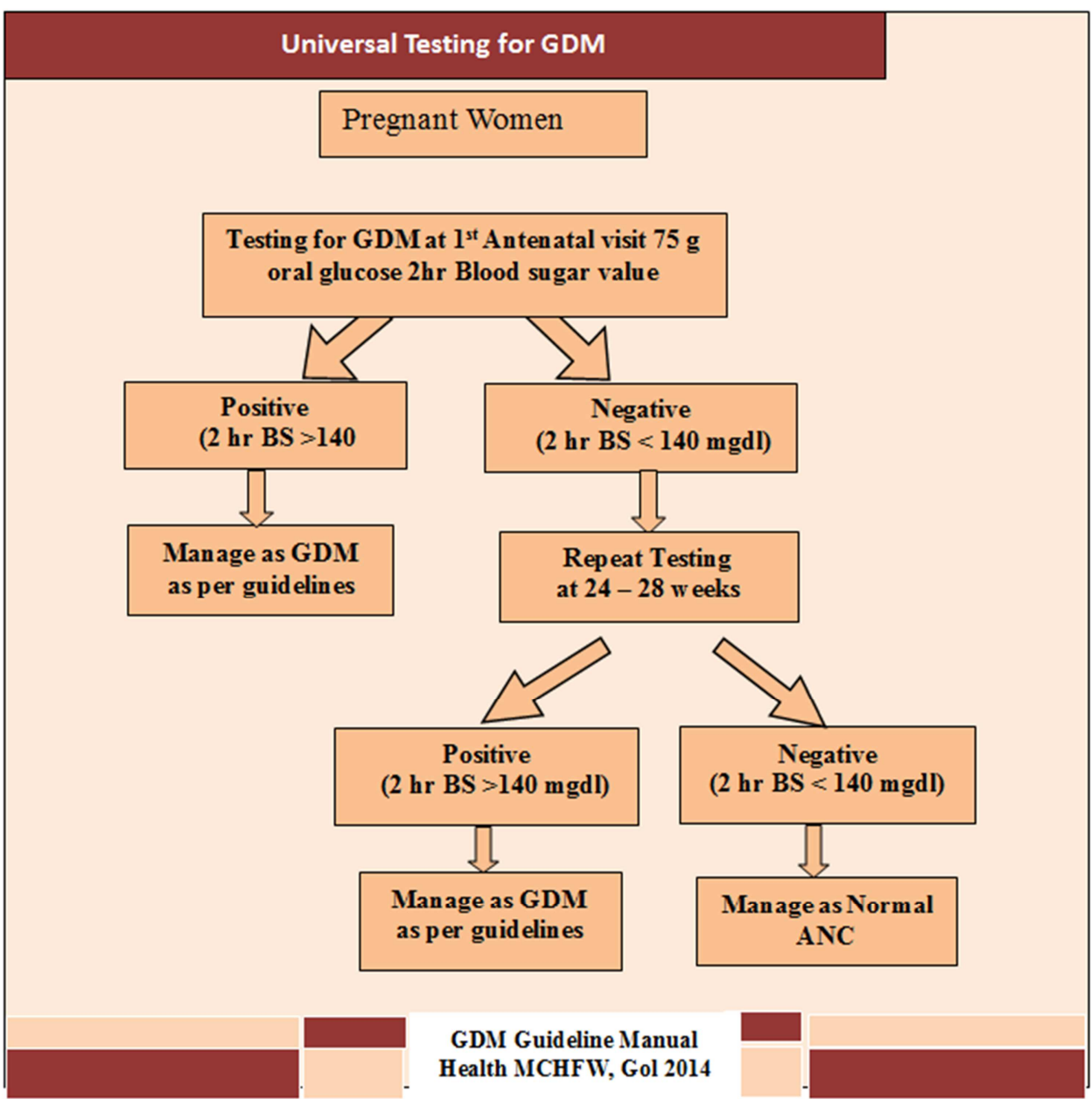

Figure 4. Universal Single test of MOHFW, Govt of India GDM Guideline Manual Health MOHFW, 2014. 


\subsection{FIGO/WHO Guidelines for GDM in Low Resource Setting}

In fully resource setting Diabetes in pregnancy can be detected by PPG or HbAIc in First trimester, and FBS is $>=$ 92 as per IADPSG Criteria for GDM diagnosis, if negative
Pregnant women is followed for $2 \mathrm{hr}$ - OGTT with $75 \mathrm{gm}$ of Glucose. In the situations where women may not be able to come for testing in a fasting state, a single step 75-g 2-hour non fasting test $(>140 \mathrm{mg} / \mathrm{dl})$ as used in India, may be applied [12].

Table 3. Option for diagnosis of gestational diabetes mellitus based on resource settings.

\begin{tabular}{|c|c|c|c|c|}
\hline \multicolumn{5}{|l|}{ Strategy } \\
\hline Setting & Who to test when & Diagnostic test & Interpretation & Grade \\
\hline Fullyresourced setting & $\begin{array}{l}\text { All women at } \\
\text { booking/first trimester }\end{array}$ & $\begin{array}{l}\text { Measure PPG, RBS, or Hbalc to detect } \\
\text { diabetes in Pregnancy }\end{array}$ & & 110 \\
\hline $\begin{array}{l}\text { Fullyresourced setting serving ethnic populations } \\
\text { at high risk }\end{array}$ & $\begin{array}{l}24 \text { week } \\
\text { All women at } \\
\text { booking/first trimester } \\
24 \text { week }\end{array}$ & $\begin{array}{l}\text { If negative: perform } 75-\mathrm{g} \text { 2hour OGTT } \\
\text { perform } 75-\mathrm{g} 2 \text { hour OGTT to detect } \\
\text { diabetes in pregnancy } \\
\text { If negative: perform } 75-\mathrm{g} \text { 2hour OGTT }\end{array}$ & & $2 \mid 000$ \\
\hline
\end{tabular}

\subsection{FIGO GDM Diagnosis Recommendation}

GDM diagnosis should be ideally based on blood tests done in an accredited laboratory on properly collected and transported venous plasma sample.

1. FIGO recommends the use of a plasma-calibrated handheld Glucometer with properly stored test strips to measure plasma glucose in primary care settings. Particularly in low-resource countries, where a closeby laboratory or facilities for proper storage and transport of blood samples to distant laboratory may not exist. This may be more convenient and reliable than tests done on inadequately handled and transported blood samples in a laboratory. It is recommended that form time to time a few samples are parallel tested in an accredited laboratory to document the variability.

2. FIGO recommend that all laboratories and clinical services document their baseline quality and work toward improvement irrespective of the recourses available.

Table 4. POINT OF CARE TESTING (POC) FOR GDM FIGO Recommendations.

Recommendation for prenatal supervision in women with Gestational diabetes mellitus:

\begin{tabular}{|c|c|c|}
\hline Recommendation & Resource setting & $\begin{array}{l}\text { Strength of recommendation } \\
\text { and quality of evidence }\end{array}$ \\
\hline $\begin{array}{l}\text { Routine prenatal care should include visit to: } \\
\text { Healthcare professionals skilled in women with diabetes in pregnancy (obstetrician, } \\
\text { penologist, dialectologist, diabetes educator, nutritionist ect.): 1-3 week as need } \\
\text { Nurse: weigh, blood pressure, dipstick urine protein: } 1-3 \text { weeks as need }\end{array}$ & High & $1 \mid 0$ \\
\hline $\begin{array}{l}\text { Parental follow-up determined locally according toavailable resource: } \\
\text { A minimum of monthly check-up with a healthcare provider knowledgeable in diabetes in } \\
\text { pregnancy }\end{array}$ & Mid and Low & $2 \mid 000$ \\
\hline
\end{tabular}

\subsection{FIGO Recommendation for Foetal Monitoring}

FIGO Recommends at least one USG for Growth every 2-4 Weeks in GDM Diagnosed cases, as it will help in Labelling of Macrosomia and Small of Gestational Age (SGA).

Table 5. Recommendation for growth assessment in women with gestational diabetes mellitus.

\begin{tabular}{lll}
\hline Recommendation & Resource setting & $\begin{array}{l}\text { Strength of recommendation and } \\
\text { quality of evidence }\end{array}$ \\
\hline Clinical and songraphic growth assessment every 2-4 weeks from diagnosis until time. & High & $1 \mid 000$ \\
Periodic clinical and sonographic growth assessment from until time. & Mid and Low & $2 \mid 000$ \\
\hline
\end{tabular}

\section{Management of GDM}

\subsection{NHM Govt of India Guidelines, Management of GDM}

National health Mission, Ministry of health \& Family Welfare, Govt of India released GDM Guidelines and
Management in which MNT is the mainstay of the Treatment once GDM is Diagnosed for 2 weeks, and after that if Blood Sugar Post Prandial failed to reach $<120 \mathrm{mg} / \mathrm{dl}$, Metformin can be initiated after 20 weeks of Pregnancy. Insulin can be added if failed to achieve target with or without metformin [12]. 
Management of GDM, Guidelines 2018 [12]

Medical Management (Oral Anti-diabetic DrugMetformin; and Insulin Therapy)

1. Metformin or Insulin therapy is the accepted medical management of pregnant women with GDM not controlled on MNT. Insulin is the first drug of choice and metformin can be considered after 20 weeks of gestation for medical management of GDM.

2. Insulin can be started any time during pregnancy for GDM management. If pregnant women with GDM before 20 weeks, and Medical Nutrition Therapy (MNT) failed, Insulin should be started.

3. Metformin can be started at 20 weeks of pregnancy, if
MNT has failed to control her blood sugar. If the woman's blood sugar is not controlled with the maximum dose of metformin (2 gm/ day) and MNT, Insulin to be added. The dose of metformin is $500 \mathrm{mg}$ twice daily orally up to a maximum of $2 \mathrm{gm} /$ day.

4. Hypoglycemia and weight gain with metformin are less in comparison to Insulin.

5. If Insulin is required in high doses, metformin may be added to the treatment.

6. At PHC, MO should initiate treatment \& refer pregnant women with GDM to a higher center if blood sugar levels are not controlled or there is some other complication.

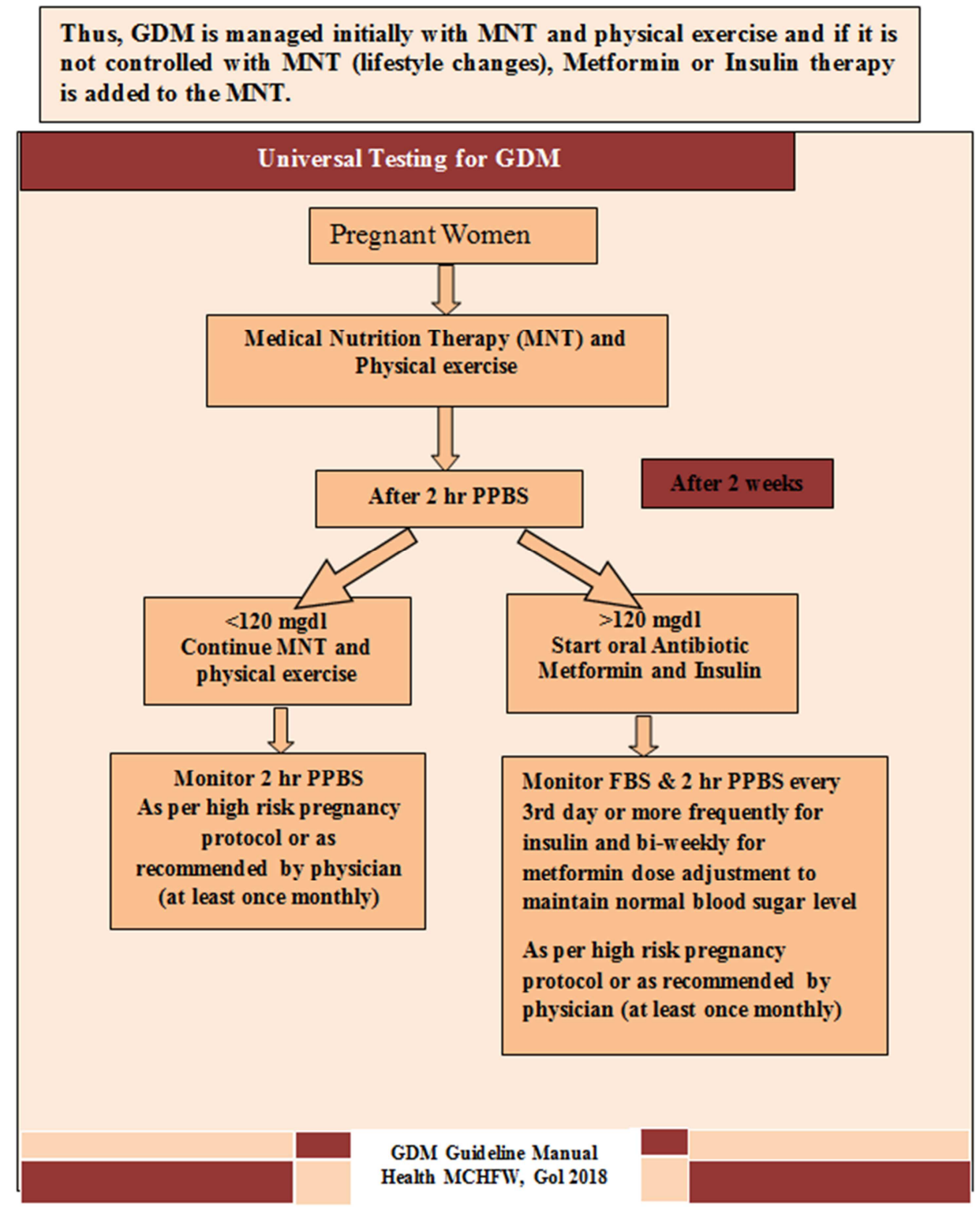

Figure 5. Medical Management of Gestational Diabetes Mellitus.

A personalised diet plan should be framed by a trained dietician, which should provide necessary healthy nutrition for the increased demand of the mother and foetus. [13]. Lifestyle modification is the most important intervention for GDM control and is sufficient to control around $70-80 \%$ of all pregnant women with GDM [13].

In Pregnant women especially those with T1DM and preexisting type 11 diabetes, ADA advocates for the use of Insulin however, changing the physiological demand in pregnancy may require more monitoring and titration of 
Insulin and should be frequently self-monitored by the women [13].

In the $1^{\text {st }}$ trimester: Generally, insulin continues in DIP but GDM rarely requires the use of insulin in Type II diabetes. T1DM may experience hypoglycaemia, therefore Insulin titration may be needed more frequently for this group.

In the $2^{\text {nd }}$ trimester: Insulin requirement increases in second trimester because of increase of anti- insulin hormones \& Placental lactogen which is increased bi- weekly or twice a week to achieve glycaemic goals. Generally, 50\% insulin given as basal dose and $50 \%$ as prandial dose to achieve good control.

Late in $3^{\text {rd }}$ trimester:

Treatment with Insulin is complex and need referral to higher centres where specialised team of Obstetrician, endocrinologist and trained Dietician is needed.

Diabetes in pregnancy is associated with high risk of preeclampsia hence women with type 1 or type 2 should be prescribed a low dose aspirin $81 \mathrm{mg}$ /day from the end of the first trimester until the baby is born (13).

In T1DMduring pregnancy the risk of hypoglycaemia is increased many folds and unawareness of hypos is also increased as counter regulatory hormone disturbances occur. Therefore patient education toward hypos are very important through pregnancy and afterwards. After delivery during the post- partumperiod placental hormones decreases and insulin resistance drops which may lead to hypos and which in turn may lead to diabetic keto-acidosis (DKA). DKA should be treated immediately in order to also prevent diabetic retinopathy [13].

GDM is not at high risk of diabetic retinopathy but DIP or pregnant women who have diabetes before conception are at increased risk of diabetic retinopathy and should thereforebe screened for diabetic retinopathy after conception earliest during the $1^{\text {st }}$ trimester and follow-up 3 monthly in NPDR and monthly in severe NPDR [14].

Family planning should be addressed to all women with HIP before conception [13]. Tight blood sugar controls; HBAIc $<6.5 \%$ for reduction of risk of outcomes like anencephaly, congenital heart disease, microcephaly and caudal regression syndrome in foetus.

\subsection{Preconception Testing}

Women with HIP with T1DM and Type II diabetes, who are planning pregnancy should be screened for diabetes retinopathy and counselled for potential progression.

Other testing and counselling is needed concerning HIV, Hepatitis B, Rubella and Pap smear, blood group, administration of folic acid $400 \mathrm{mcg}$ daily. Testing HBA1c, TSH, Urine albumin and creatinine.

Teratogenic drugs in pregnancy like ACE inhibitors, ARB [15], statin should be avoided [16], monitoring for diabetic retinopathy before the pregnancy, Use of Anti-hypertensive medication which is indicated in pregnancy i.e methyl dopa, Labetalol, Diltiazem, Prazosin and Clonidine should be followed, use of chronic diuretic should be stopped as it restricts utero-placental perfusion.

T1DM and Type II Diabetes during diabetes in pregnancy (DIP) leads to more risk in mother and foetus compare to GDM, adverse outcomes includes abortion, foetal malformations, preeclampsia, macrosomia, raised bilirubin and neonatal hypoglycaemia (18) and in futures it increases risk of Type II Diabetes and obesity in mothers and offspring's [18].

All the Women \& adolescent with diabetes risk during the reproductive period should be educated about outcomes of unplanned pregnancies [18], Preconception counselling is very effective method to reduce health cost and burden of complication associated with hyperglycaemia in pregnancy \& offspring, family planning methods should be negotiated until the women become pregnant [18].

\subsection{Diabetes in Preeclampsia \& Use of Aspirin}

DIP (Diabetes in Pregnancy) is also linked with greater risk for preeclampsia [19] as a results of clinical trial and therefore US Preventive Task force suggest use of $81 \mathrm{mg} /$ day aspirin after 12 weeks of gestation for women high risk for preeclampsia [20].

Recommendation: Level of evidence A

Type I or Type II diabetes Women should be given aspirin $60-150 \mathrm{mg} / \mathrm{daily}$ or usually $81 \mathrm{mg} / \mathrm{dl}$ to lower risk of preeclampsia since first trimester onwards.

\subsection{Medical Nutrition Therapy}

MNT (Medical Nutrition therapy) is personalised Diet plan prescribed by Dietician trained in nutrition \& Diet for the management of Gestational Diabetes Mellitus [24]. Diet plan should be based on adequate healthy nutrition and calories intake for appropriate weight. Although research is lacking whether GDM have different calories intake compare to NonGDM therefore diet plan should be as per Dietary Reference Intake which recommend at least $175 \mathrm{gm}$ of carbohydrate, minimum protein of $71 \mathrm{gm}$ and 28 gram of Fibers. It's is common that amount of carbohydrates will leads to post prandial glucose excursions [24].

Table 6. Nutritional Therapy Recommendations, FIGO.

Recommendations for nutrition in women with gestational diabetes mellitus

\begin{tabular}{|c|c|c|}
\hline Recommendation & $\begin{array}{l}\text { Resource } \\
\text { setting }\end{array}$ & $\begin{array}{l}\text { Strength of recommendation } \\
\text { and quality of evidence }\end{array}$ \\
\hline $\begin{array}{l}\text { We recommended that the following principals should be adhered for all pregnant women with } \\
\text { diabetes: }\end{array}$ & & \\
\hline
\end{tabular}




\begin{tabular}{|c|c|c|}
\hline Recommendation & $\begin{array}{l}\text { Resource } \\
\text { setting }\end{array}$ & $\begin{array}{l}\text { Strength of recommendation } \\
\text { and quality of evidence }\end{array}$ \\
\hline \\
\hline $\begin{array}{l}\text { 3. Offer training, education, support and follow-up by a qualified dietician expirees in care of women } \\
\text { with diabetes. issues for discussion include: weight control, food records, carbohydrate counting, } \\
\text { prevention of hypoglycemia, healthy foods, and physical activity }\end{array}$ & & \\
\hline \multicolumn{3}{|l|}{$\begin{array}{l}\text { We suggest that caloric intake be calculated based on pregnancy BMI and desirable weight gain as } \\
\text { follows: }\end{array}$} \\
\hline 1. $35-40 \mathrm{kcal} / \mathrm{kg}$ desirable body weight for underweight women & All & $2 \mid 00$ \\
\hline 2. $30-35 \mathrm{kcal} / \mathrm{kg}$ desirable body weight for normal weight women & & \\
\hline 3. $25-30 \mathrm{kcal} / \mathrm{kg}$ desirable body weight for overweight women & & \\
\hline $\begin{array}{l}\text { We recommended limiting carbohydrate in take to total calories, with a minimum of } 175 \text { carbohydrate } \\
\text { per day, distribiuted in three small-to-moderate size meals and } 2-4 \text { snacks. }\end{array}$ & All & $1 \mid 0$ \\
\hline For obese women, caloric intake may be reduced by $30 \%$, but not below $1600-1800 \mathrm{kcal} / \mathrm{d}$ & All & 200 \\
\hline For women with diabetic nephropathy, protein me be lowered to $0.6-0.8 \mathrm{~g} / \mathrm{kg}$ ideal body weight & All & 2000 \\
\hline
\end{tabular}

1. FIGO recognized that nutrition counseling and physical activity are the primary tools in the management of GDM.

2. FIGO recommend that women GDM receive practical to nutrition education and counseling that empowers them to choose the right quality and quality of food .

3. Women with GDM must be repeatedly advised to continue the same healthy eating habits after delivery to reduce the risk for future T2DM

\subsection{Physical Activity for GDM}

Physical activity is recommended to all the Pregnant Women with GDM preferably 30 minutes every day, brisk walking is helpful after meal to lower Post Prandial Glucose Excursions. Women with Diabetes in Pregnancy should continue their previous Exercise Plan as before the Pregnancy.

Table 7. FIGO Recommendation for Physical Activity in HIP.

\begin{tabular}{lll}
\hline Recommendation & Resource setting & $\begin{array}{l}\text { Strength of recommendation and } \\
\text { quality of evidence }\end{array}$ \\
\hline We suggest that appropriate, personally adapted, physical activity be recommended for & \\
all women with diabetes: & All & $2 \mid 00$ \\
1. Planed physical activity of 30 min/day & \\
2. Brisk walking or arm exercises white seated in a chair for 10 min after each meal. \\
$\begin{array}{l}\text { 3. Women physical activity prior to pregnancy should be encouraged to continue their } \\
\text { previous exercise routine. }\end{array}$
\end{tabular}

\section{Pharmacological Management}

Pharmacologic treatment in HIP with large insulin increase may need early initiation of oral drugs. Such treatment has demonstrated better outcome in perinatal women in two randomised trials by the US Preventive Task Force Review. Insulin is the initial drug of choice as per ADA Guidelines and US Preventive Task Force advocate safety and efficacy of Metformin and Glibenclamide [25, 26] in GDM, but both pass the placenta. Another randomised trial showed that Metformin and Glibenclamide are both effective and reduced insulin use but Metformin was more effective as it causes less hypoglycaemia compared to Glibenclamide [26]. However, more definitive studies are required in this area. Long-term safety data are not available for any oral agent [27].

If Lifestyle Modification alone fails to achieve glucose control, Metformin is a better option compared to Glibenclamide and insulin and should be considered as safe and effective treatment options for GDM. GOI- MOHFW, has Introduced Metformin as $1^{\text {st }}$ line drug for GDM treatment after MNT failed to control Blood sugar $<120 \mathrm{mg} / \mathrm{dl}$ after two weeks [12].

Table 8. FIGO Recommendations for Oral Drugs in GDM.

Recommendation for pharmacological treatment in women with gestational diabetes mellitus

\begin{tabular}{lll}
\hline Recommendation & Resource setting & $\begin{array}{c}\text { Strength of recommendation and } \\
\text { quality of evidence }\end{array}$ \\
\hline $\begin{array}{l}\text { Insulin glyburide, and motorman are safe and effective therapies for GDM during the } \\
\text { second and third trimester, and may be initiated as first-line treatment after failing to } \\
\text { achieve glucose control with lifestyle modification. Among OADS, metformin may be } \\
\text { a better choice than glyburide [109] }\end{array}$ & All \\
Insulin should be consideredas the first-line treatment in women with GDM who are at \\
high risk of falling on OAD therapy, including some of the following factors [129]: \\
$\begin{array}{l}\text { 1. Diagnoses of diabetes }<20 \text { week of gestation } \\
\text { 2. Need for pharmacologic therapy }>30\end{array}$ \\
$\begin{array}{l}\text { 3. Fasting plasma glucose levels }>110 \mathrm{mg} / \mathrm{dl} \\
\text { 4. hour postprandial glucose }>140 \mathrm{mg} / \mathrm{dl}\end{array}$ \\
\begin{tabular}{l} 
5. Pregnancy weight gain $>12$ \\
\hline
\end{tabular}
\end{tabular}




\subsection{Sulfonylureas}

Titre of Glibenclamide in umbilical cord plasma is around $70 \%$ of maternal levels and is therefore linked with the higher level of neo-born hypoglycaemia and LGA (macrosomia) if we compare with Metformin or Insulin in review (28).

\subsection{Metformin}

Metformin was associated with a lower risk of neonatal hypoglycaemia and less maternal weight gain compare to insulin in systematic meta-analysis (2015) (28); although, Metformin increased the risk of prematurity or birth less than 37 weeks of gestation. Metformin is however not sufficient to control blood sugar less than $120 \mathrm{mg} / \mathrm{dl}$ in GDM and therefore additional insulin is neededto control blood sugar to reach target level [25].

\section{Gestational Diabetes Mellitus and Type 2 Diabetes}

In Nurse health study II Women with history of GDM was found to be at increased risk for future Type II diabetes but risk decreased with women with GDM who followed healthy diet \& lifestyle when normalised for BMI risk was reduced but small risk still remained [21].

Postpartum weight increased was associated with bad outcomes in future pregnancies [21] and Risk for Type II Diabetes.

\subsection{Postpartum Care \& Lactation}

Postpartum care should include OGTT (75 gm Glucose Load in fasting state) after 6 weeks of delivery [12], to know the status of Diabetes. Psychological counselling and breastfeeding are very important for provide long metabolic \& Immunological advantage for mother [22] and children [22] which reduces the chances of Type II Diabetes later in life.

\subsection{Pre-conception and Inter-pregnancy Recommendations (FIGO)}

FIGO calls for public health measures to increase awareness and acceptance of preconception consulting and to increase affordability and access to preconception service to women of productiveage, as this is likely to have both immediate and lasting benefits for material and child health.
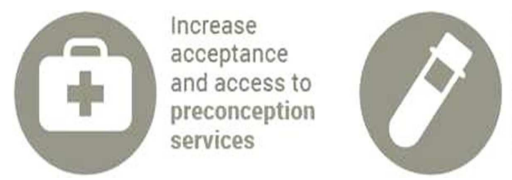

Universal pre-conception screening for malnutrition anemia, overweight and obesity, hypertension, diabetes and thyroid dysfunction

Figure 6. Preconception Counseling.

\section{Conclusion}

There are around 5.5 million cases of HIP hyperglycaemia in pregnancy annually in South Asia. It is a great challenge to screen all pregnant women and manage these if needed. Furthermore, it is difficult to screen pregnant women in fasting state and the fasting blood sugar in most of South Asian women is not abnormal compared to OGTT after 2hour of $75 \mathrm{gm}$ Glucose load, Moreover, using this method of Testing is able to detect most of pregnant women with HIP (hyperglycaemia in pregnancy). FIGO and IDF therefore endorses the DIPSI test especially in resource limited settings of South Asia and other countries, whereas the IADPSG criteria is not suitable for Asian countries as pregnant Women has to go 3 times for testing which is even not practical in a European setting and large number of pregnant women do also not come in fasting state. In India two States; Tamil Nadu and Uttar Pradesh have launched Universal GDM testing and pregnant women are here detected GDM and followed-up for blood sugar control during the pregnancy and most women $(90 \%)$ are managed with MNT (Medical Nutrition Therapy). The remaining group where the post prandial Blood sugar (2hour) is $>120 \mathrm{mg} / \mathrm{dl}$ after 2 weeks of MNT, receive Metformin and Insulin for GDM treatment, A large number of ANMs has been recruited to address maternal health issues like hypertension in pregnancy, anaemia, malnutrition, over-nutrition and hyperglycaemia of pregnancy. 28,000 ANMs are being trained to cater for an estimated6 million pregnant women alone in the Uttar Pradesh., Till now, 1 million pregnant women have been screened in UP. UP is following the Tamil Nadu model, where Dr. V Seshiah; father of GDM in India started a GDM program in 2007 with the Tamil Nadu Government., Recently the Govt of India declared Dr. V Seshiahs birthday, the $10^{\text {th }}$ of March as Indian GDM awareness day.

\section{Conflict of Interest}

No conflict of interest in Preparation of Manuscript involved.

\section{Acknowledgements}

The support of the maternal health, National health Mission, MOHFW, Govt of India is well appreciated for providing revised Guidelines for GDM, 2018.

\section{References}

[1] Hod M, Kapur A, Sacks DA, et al. The International Federation of Gynaecology and Obstetrics (FIGO) Initiative on gestational diabetes mellitus: A pragmatic guide for diagnosis, management, and care.

[2] Guariguata L, Linnenkamp U, Beagley J, et al. Global estimates of the prevalence of hyperglycaemia in pregnancy. Diabetes Res Clin Pract 2014; 103: 176-85. 
[3] American Diabetes Association. Diagnosis and Classification of Diabetes Mellitus. Diabetes Care 2003; 25: s5-s20.

[4] World Health Organization. Diagnostic criteria and classification of hyperglycaemia first detected in pregnancy. World Health Organization, 2013; WHO/NMH/MND/13.2.

[5] Fetita LS, Sobngwi E, Serradas P, et al. Consequences of fetal exposure to maternal diabetes in offspring. J Clin Endocrinol Metab 2006; 91: 3718-24.

[6] IDF 2017 International Diabetes Federation IDF Diabetes Atlas 8th ed. http://www.idfatlas.org

[7] Magee, MS., Walden, CE. (1993) 'Influence of diagnostic criteria on the incidence of gestational diabetes and perinatal morbidity', JAMA, 269 (5), pp. 609-15.

[8] Mohan, V., Sandeep S, (2007) 'Epidemiology of type 2 diabetes: Indian scenario. Indian J Med Res', 125, pp. 217-30.

[9] Haeusler, M., Weiss, PA. (2000). 'Can glucose tolerance test predict fetalhyperinsulinism?' BJOG, 107 (12), pp. 1480-5.

[10] Behera, MK., Das, S, and Misra, S. (2010)'B-cell function and insulin resistance in pregnancy and their relation to fetal development', Metab Syndr Relat Disord, 8 (1), pp. 25-32.

[11] Anjalakshi, C., Balaji V and Balaji M. (2011) 'Inadequacy of fasting plasma glucose to diagnose gestational diabetes mellitus in Asian Indian Women', Diabetes Res Clin Pract, 94 (1), pp. 21-3.

[12] Maternal health Division (2018) 'Diagnosis \& Management of Gestational Diabetes Mellitus Technical and Operational Guidelines', Ministry of health \& family Welfare, GOI.

[13] American Diabetes Association 'Management of diabetes in pregnancy: Standards of Medical Care in Diabetes 2018'. Diabetes Care 2018; 41 (Suppl. 1): S137-S143.

[14] AAO 2014 'Screening for Diabetic retinopathy, American Association of Ophthalmology, www.aao.org/clinical statement.

[15] Bullo M, Tschumi S, Bucher BS, Bianchetti MG, Simonetti GD. Pregnancy outcome following expo- sure to angiotensinconverting enzyme inhibitors or angiotensin receptor antagonists: a systematic review. Hypertension 2012; 60: 44445 .

[16] Kazmin A, Garcia-Bournissen F, Koren G. Risks of statin use during pregnancy: a systematic review. J Obstet Gynaecol Can 2007; 29:906-908.
[17] Charron-Prochownik D, Downs J. Diabetes and Reproductive Health for Girls. Alexandria, VA, American Diabetes Association, 2016.

[18] Dabelea D, Hanson RL, Lindsay RS, et al. Intra- uterine exposure to diabetes conveys risks for type 2 diabetes and obesity: a study of discordant siblings. Diabetes 2000; 49: 2208-2211.

[19] Duckitt K, Harrington D. Risk factors for pre- eclampsia at antenatal booking: systematic re- view of controlled studies. BMJ 2005; 330: 565.

[20] Henderson JT, Whitlock EP, O'Conner E, Senger CA, Thompson JH, Rowland MG. Low- dose aspirin for the prevention of morbidity and mortality from preeclampsia: a systematic evidence review for the U.S. Preventive Services Task Force [article online], 2014. Rockville, MD: Agency for Healthcare Research and Quality. Available from http://www.ncbi.nlm.nih.gov/books/NBK196392/.

[21] Villamor E, Cnattingius S. Interpregnancy weight change and risk of adverse pregnancy out- comes: a population-based study. Lancet 2006; 368: 1164-1170.

[22] Stuebe AM, Rich-Edwards JW, Willett WC, Manson JE, Michels KB. Duration of lactation and incidence of type 2 diabetes. JAMA 2005; 294: 2601-2610.

[23] Pereira PF, Alfenas R de CG, Arau'jo RMA. Does breastfeeding influence the risk of developing di- abetes mellitus in children? A review of current evidence. J Pediatr (Rio J) 2014; 90: 7-15.

[24] Han S, Crowther CA, Middleton P, Heatley E. Different types of dietary advice for women with gestational diabetes mellitus. Cochrane Database Syst Rev 2013; 3: CD009275.

[25] Rowan JA, Hague WM, Gao W, Battin MR, Moore MP; MiG Trial Investigators. Metformin versus insulin for the treatment of gestational diabetes. N Engl J Med 2008; b358: 2003-2015.

[26] Gui J, Liu Q, Feng L. Metformin vs insulin in the management of gestational diabetes: a meta- analysis. PLoS One 2013; 8: e64585.

[27] Nachum Z, Zafran N, Salim R, et al. Glyburide versus metformin and their combination for the treatment of gestational diabetes mellitus: a randomized controlled study. Diabetes Care 2017; 40: 332-337.

[28] Balsells M, Garc'ia-Patterson A, Sola' I, Roque' M, Gich I, Corcoy R. Glibenclamide, metformin, and insulin for the treatment of gestational diabetes: a systematic review and meta-analysis. BMJ 2015; 350: h102. 